\title{
PENGUJIAN PEMBANGKITAN TEGANGAN GENERATOR AXIAL-FLUX PERMANENT MAGNET (AFPM) TIGA-FASA GANDA
}

\author{
I M. W. Kastawan ${ }^{1}$, Rusmana ${ }^{1}$ \\ 'Jurusan Teknik Konversi Energi, Politeknik Negeri Bandung \\ Jl. Gegerkalong Hilir, Bandung Barat, Jawa Barat, Indonesia \\ e-mail: wiwit.kastawan@polban.ac.id, rusmana@polban.ac.id
}

\begin{abstract}
ABSTRAK
Tulisan ini membahas tentang pembuatan generator axial-flux permanent magnet (AFPM) yang dapat menghasilkan dua buah tegangan tiga-fasa dengan pergeseran sudut $30^{\circ}$ atau lazim dikenal sebagai tiga-fasa ganda. Tipe generator AFPM yang dibuat adalah double sided internal rotoryang memiliki sebuah piringan rotor untuk menempatkan kutub-kutub magnet generator yang diapit oleh dua buah piringan statoryang digunakan untuk menempatkan dua buah belitan jangkar tiga-fasa. Generator ini memiliki 18 kutub magnet sehingga jarak antara dua buah kutub magnet yang saling berdekatan adalah $20^{\circ}$ mekanik. Oleh karenanya untuk menghasilkan tegangan keluaran tiga-fasa maka belitan-belitan fasa $R, S$ dan $T$ pada masing-masing piringan stator akan berjarak $13,3^{\circ}$ mekanik. Lebih lanjut, untuk menghasilkan pergeseran fasa $30^{\circ}$ di antara kedua buah tegangan keluaran tiga-fasa generator maka belitan tiga-fasa pada piringan stator pertama dan kedua harus diberi pergeseran sudut sebesar $3,3^{\circ}$ mekanik. Hasil uji laboratorium menunjukkan bahwa generator AFPM yang dibuat mampu menghasilkan dua buah tegangan tiga-fasa berfrekuensi $50 \mathrm{~Hz}$ pada putaran $339 \mathrm{rpm}$ (rotation per-minute) yaituR $R_{I}=44,9 \angle 0^{\circ} \mathrm{V}, S_{l}=39,8 \angle-118^{\circ} \mathrm{V}$ dan $T_{l}=44,0 \angle-237^{\circ}$ dengan total harmonic distortion (THD) sebesar $3,4 \%$ serta $R_{2}=42,8 \angle-32^{\circ} \mathrm{V}, S_{2}=42,7 \angle-153^{\circ} \mathrm{Vdan} T_{2}=42,6 \angle-272^{\circ}$ $V$ dengan THD sebesar 2,1\%. Hasil pengujian ini menunjukkan bahwa generator mampu membangkitkan dua buah tegangan keluaran tiga-fasa yang memiliki bentuk gelombang mendekati sinusoidal murni dengan keseimbangan magnituda dan fasa cukup baik karena rata-rata penyimpangannya masing-masing hanya sebesar $1,5 \mathrm{~V}(2,5 \%)$ dan $2,4^{\circ}(1,7 \%)$.
\end{abstract}

Kata kunci: generator AFPM, double sided internal rotor, tegangan tiga-fasa ganda.

\section{PENDAHULUAN}

Berbeda dengan generator yang telah umum kita kenal, generator axial-flux permanent magnet (disingkat AFPM)memiliki aliran fluksi atau medan magnetik yang searah dengan sumbu atau poros generator. Fluksi pada generator AFPM ini diperoleh dari kutubkutub magnet permanen sehingga tidak diperlukan penggunaan sumber eksitasi luar. Dengan jumlah kutub magnet permanen yang cukup banyak maka generator AFPM akan mampu bekerja pada putaran yang cukup rendah sehingga dinilai cocok untuk diaplikasikanpada pembangkit listrik tenaga angin atau pembangkit listrik tenaga air berkapasitas kecil (mikrohidro) yang memanfaatkan energi dari aliran air sungai berelevasi rendah [1],[2].

Secara umum generator AFPM memiliki konstruksi yang lebih sederhana jika dibandingkan dengan generator konvensional fluksi radial. Sebuah generator AFPM dengan tipe satu-fasa single sided hanyaakan terdiri dari sebuah piringan rotor untuk menempatkan kutub-kutub magnet permanen dan sebuah piringan stator untuk menempatkan belitanbelitan jangkar dimana tegangan dibangkitkan
[3] - [5].Generator ini dapat dengan mudah dikembangkan lebih lanjut, misalnya menjadi generator AFPM tiga-fasa single sided dengan mengatur penempatan belitan-belitan jangkarnya di piringan stator pada sudut-sudut mekanik yang tepat sehingga dihasilkan tiga buah tegangan sinusoidal dengan beda fasa mendekati $120^{\circ}$. Namun, pengembangan dengan cara ini relatif jarang dilakukan karena untuk menghasilkan tegangan dan daya keluaran generator yang cukup besar akan diperlukan belitan jangkar dengan jumlah lilitan cukup banyak dan/atau kutub-kutub magnet permanen yang lebih kuat sehingga menyulitkan penempatannya pada piringan stator. Untuk menghasilkan tegangan keluaran tiga-fasa atau lebih, generator AFPM umumnya dikembangkan menjadi tipe double sided atau multidisc. Generator AFPM double sided memiliki tiga buah piringan. Komposisinya dapat terdiri dari dua buah piringan stator dan satu buah piringan rotor (dikenal sebagai tipe double sided internal rotor) atau dua buah piringan rotor dan satu buah piringan stator (dikenal sebagai tipe double sided internal stator). Sementara itu, generator AFPM multidisc memiliki jumlah 
piringan stator dan rotor lebih dari tiga sehingga konstruksinya menjadi jauh lebih rumit meski kemampuan tegangan dan daya keluarannya menjadi lebih besar lagi [3],[4]. Pengembangan generator AFPM tiga-fasa tipe double sided internal rotor dan double sided internal stator telah berhasil dilakukan. Kedua generator AFPM double sided ini mampu menghasilkan tegangan keluaran tiga-fasa yang memiliki bentuk gelombang mendekati sinusoidal murni dengan keseimbangan magnituda dan fasa cukup baik [6],[7]. Generator ini dapat dikembangkan lebih lanjut menjadi generator AFPM double sided yang dapat menghasilkan tegangan keluaran dengan jumlah fasa lebih banyak lagi, misalnya tigafasa ganda yaitu dua buah tegangan keluaran tiga-fasa yang memiliki pergeseran fasa tertentu. Untuk tipe double sided internal rotor, tegangan keluaran tiga-fasa pertama dapat diperoleh dari belitan-belitan jangkar tiga-fasa yang ditempatkan pada piringan stator pertama sementara tegangan keluaran tiga-fasa yang kedua dapat diperoleh dari belitan-belitan jangkar tiga-fasa yang ditempatkan pada piringan stator kedua. Untuk tipe double sided internal stator yang hanya memiliki sebuah piringan stator maka belitan-belitan jangkar tiga-fasa yang pertama dapat ditempatkan pada salah satu sisi permukaan piringan stator sementara belitan-belitan jangkar tiga-fasa yang kedua ditempatkan pada sisi permukaan piringan stator yang lainnya. Dalam tulisan ini akan diuraikan langkah-langkah pengembangan generator AFPM tipe double sided internal rotor yang dapat menghasilkan dua buah tegangan tiga-fasa dengan pergeseran sudut $30^{\circ}$ di antara keduanya.

\section{GENERATOR AFPM DOUBLE SIDED INTERNAL ROTOR DENGAN TEGANGAN KELUARAN TIGA-FASA GANDA}

Konstruksi dari sebuah generator AFPM double sided internal rotorditunjukkan oleh Gambar 1. Generator ini memiliki sebuah piringan rotor yang diapit oleh dua buah piringan stator. Pada piringan rotor dibuat sejumlah lubang dengan ukuran tertentu untuk menempatkan kutub-kutub magnet generator. Dengan demikian kutub-kutub magnet akan menghadap ke kedua sisi permukaan dari piringan rotor. Sementara itu, pada piringan stator akan ditempatkan belitan-belitan jangkar sebagai tempat terbangkitkannya tegangan keluaran generator AFPM. Belitan-belitan jangkar ini hanya ditempatkan pada satu sisi permukaan piringan stator, yaitu sisi permukaan yang menghadap ke salah satu dari dua sisi permukaan piringan rotor. Untuk menghasilkan celah udara di antara piringan rotor dan piringan stator yang seragam dan sesempitmungkin maka kutub-kutub magnet generator AFPM harus dipasang secara embedded pada piringan rotor sementara belitan-belitan jangkarnya dipasang secara slotted pada piringan stator.

Untuk menghasilkan tegangan keluaran tiga-fasa ganda maka pada setiap piringan stator akan ditempatkan belitanbelitan jangkar tiga-fasa. Belitan tiga-fasa pada piringan stator pertama akan memiliki pergeseran fasa tertentu dari belitan-belitan jangkar tiga-fasa di piringan yang kedua. Besarnya tegangan per-fasa yang dibangkitkan generator adalah bergantung pada jumlah lilitan untuk setiap fasa belitan jangkar $\left(N_{w}\right)$, kecepatan putaran penggerak generator $(n)$ dan kuat medan magnetik yang dihasilkan oleh kutub-kutub magnet permanen generator $\left(\Phi_{m}\right)$ sesuai persamaan (1) berikut ini:

$E_{a}=k n N_{w} \Phi_{m}$

dengan $k$ menyatakan sebuah nilai konstan. Sementara itu, jumlah dari kutub magnet yang digunakan $(p)$ akan menentukan frekuensi dari gelombang tegangan keluaran yang dibangkitkan generator AFPM sesuai persamaan (2) berikut ini:

$f=\frac{n p}{120}$

Berdasarkan persamaan (2) di atas, generator AFPM akan dapat bekerja pada putaran yang relatif rendah jika jumlah kutub-kutub magnet yang digunakan lebih banyak. Lebih lanjut, penggunaan kutub-kutub magnet dengan jumlah yang cukup banyak dan bentuk mendekati juring lingkaran akan menghasilkan distribusi fluksi yang lebih merata dan seragam sehingga tegangan keluaran generator yang dibangkitkan lebih mendekati bentuk sinusoidal. 


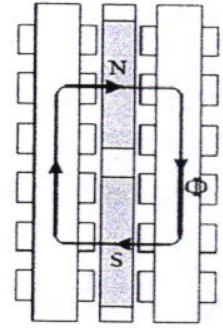

Gambar 1. Konstruksi generator AFPM double sided internal rotor [3].

Generator AFPM double sided internal rotor tiga-fasa ganda yang dibuat memiliki 18 buah kutub magnet permanen. Generator ini diharapkan mampu membangkitkan dua buah tegangan keluaran tiga-fasa dengan frekuensi $50 \mathrm{~Hz}$ dan pergeseran fasa $30^{\circ}$ pada belitanbelitan jangkar yang ditempatkan di kedua buah piringan stator. Dengan mengacu pada persamaan (2) maka kecepatan putaran generator akan berkisar $333 \mathrm{rpm}$ (rotationperminute). Masing-masing kutub magnet permanen yang digunakan berjenis magnet keramik dengan bentuk balok persegi berukuran $50 \mathrm{~mm} \times 30 \mathrm{~mm} \times 14 \mathrm{~mm}$. Ke-18 buah kutub magnet permanen ini dipasangkan secara embedded atau tertanam di sekeliling piringan rotor berdiameter $300 \mathrm{~mm}$ dengan ketebalan $14 \mathrm{~mm}$. Dengan demikian, jarak antara dua buah kutub magnet permanen yang saling berdekatan adalah sama dengan $20^{\circ}$. Pada titik pusat piringan rotor dibuat lubang poros dengan diameter $20 \mathrm{~mm}$. Gambar 2 menunjukkan piringan rotor dan kutub-kutub magnet permanen dari generator AFPM double sided internal rotor tiga-fasa ganda yang dibuat.

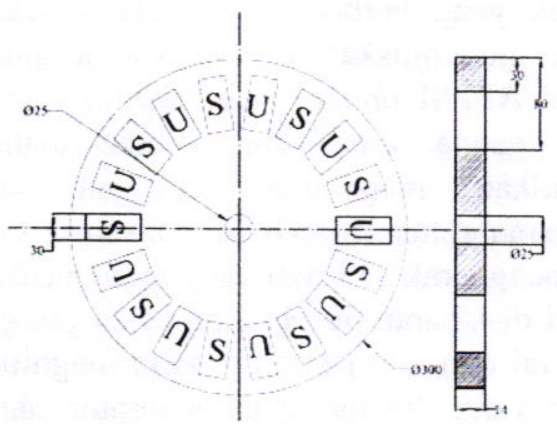

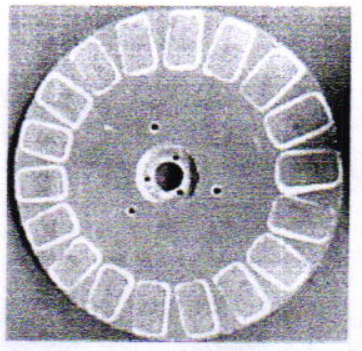

Gambar 2. Piringan rotor dan kutub-kutub magnet permanen generator AFPM double sided internal rotor tiga-fasa ganda.

Sementara itu, Gambar 3 menampilkan kedua buah piringan stator beserta belitanbelitan jangkar tiga-fasa dari generator AFPM double sided internal rotor tiga-fasa gandayang dibuat. Masing-masing piringan stator memiliki diameter luar $339 \mathrm{~mm}$ dan diameter dalam $180 \mathrm{~mm}$ dengan ketebalan $20 \mathrm{~mm}$. Pada titik pusat piringan stator dibuat lubang poros dengan diameter $20 \mathrm{~mm}$. Kedalaman piringan stator berukuran $16 \mathrm{~mm}$ untuk menempatkan belitan-belitan jangkar agar tidak menonjol ke keluar melebihi ketebalan piringan stator.Setiap belitan jangkar generator terbuat dari 750 lilitan kawat tembaga berisolasi. Setiap fasa tegangan keluaran generator terbentuk dari 8 buah belitan jangkar yang terhubung seri sehingga jumlah lilitan per-fasa adalah sebanyak 6000 . Dengan demikian untuk menghasilkan tegangan keluaran tiga-fasa ganda akan dibutuhkan total sebanyak 48 belitan jangkar. Masing-masing belitan jangkar ini berbentuk persegi dengan ukuran $50 \mathrm{~mm} \times$ $30 \mathrm{~mm}$ sesuai bentuk dan ukuran dari kutubkutub magnet permanen yang digunakan. Belitan-belitan jangkar ini ditempatkan pada kedua piringan stator pada sudut-sudut mekanik yang ditampilkan oleh Tabel 1 untuk menghasilkan dua buah tegangan keluaran tigafasa yaitu $R_{1}, S_{1}, T_{1}$ dan $R_{2}, S_{2}, T_{2}$ yang memiliki pergeseran fasa $30^{\circ}$.

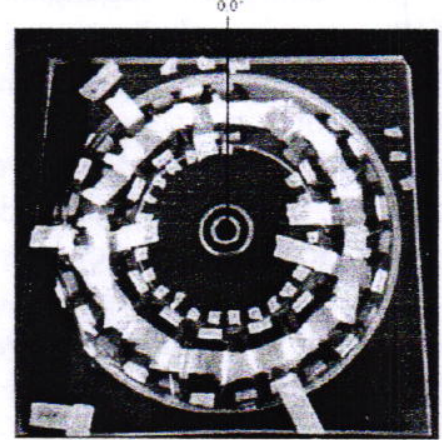




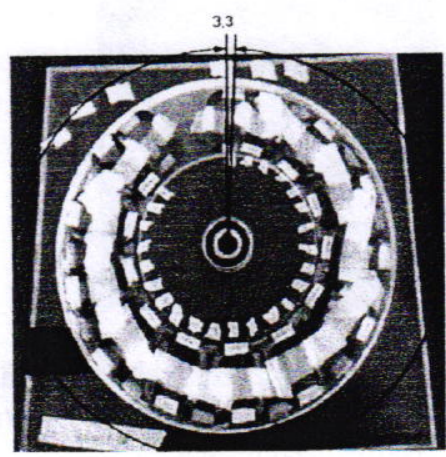

Gambar 3. Piringan stator ke-1 dan ke-2 dengan belitan-belitan jangkar tiga-fasa dari generator AFPM double sided internal rotor tiga-fasa ganda.

Tabel 1. Sudut-sudut mekanik untuk penempatan belitan jangkar pada piringan stator generator AFPM double sided internal rotor tiga-fasa ganda.

\begin{tabular}{|c|c|c|c|c|c|c|}
\hline \multirow{2}{*}{$\begin{array}{l}\text { Belitain } \\
\text { dangikar }\end{array}$} & \multicolumn{6}{|c|}{ Sudut nekanik $(9)$ untrik masing minsing face } \\
\hline & $\mathrm{R}_{2}$ & St. & 1, & Ris & She & $\mathrm{H}_{2}$ \\
\hline Ke-1 & 0 & 13.3 & 26.6 & 3.3 & 16.6 & 29.9 \\
\hline $\mathrm{Ke}-2$ & 40 & 53.3 & 66.6 & 43.3 & 56.6 & 69.9 \\
\hline $\mathrm{Ke}-3$ & so & 93.3 & 106.6 & 83.3 & 96.6 & 109.9 \\
\hline $\mathrm{Ke}-4$ & 120 & 133.3 & 146.6 & 123.3 & 136.6 & 149.9 \\
\hline Ke-5 & 160 & 173.3 & 186.6 & 163.3 & 176.6 & 189.9 \\
\hline Ke-6 & 200 & 213.3 & 226.6 & 203.3 & 216.6 & 229.9 \\
\hline Ke-7 & 240 & 253.3 & 266.6 & 243.3 & 256.6 & 269.9 \\
\hline Ke-s & 280 & 293.3 & 306.6 & 283.3 & 296.6 & 309.9 \\
\hline
\end{tabular}

Piringan rotor dan kedua piringan stator ini selanjutnya dirakit menjadi sebuah unit generator AFPM double sided internal rotor tiga-fasa ganda yang utuh dengan menggunakan poros generator dan penyangga rotor untuk pengujian laboratorium.

\section{PENGUJIAN DAN ANALISIS}

Gambar 4 di bawah ini menunjukkan skema uji laboratorium untuk mengetahui kemampuan pembangkitan tegangan dari generator AFPM double sided internal rotor tiga-fasa ganda yang telah dibuat. Generator dikopel dengan motor penggerak yang memiliki kecepatan yang dapat diatur. Kecepatan putaran generator diukur dengan Tachometer sementara tegangan keluaran tigafasa ganda yang dihasilkan diukur dengan unit instrumentasi dijital PQ (Power Quality) Analyser.
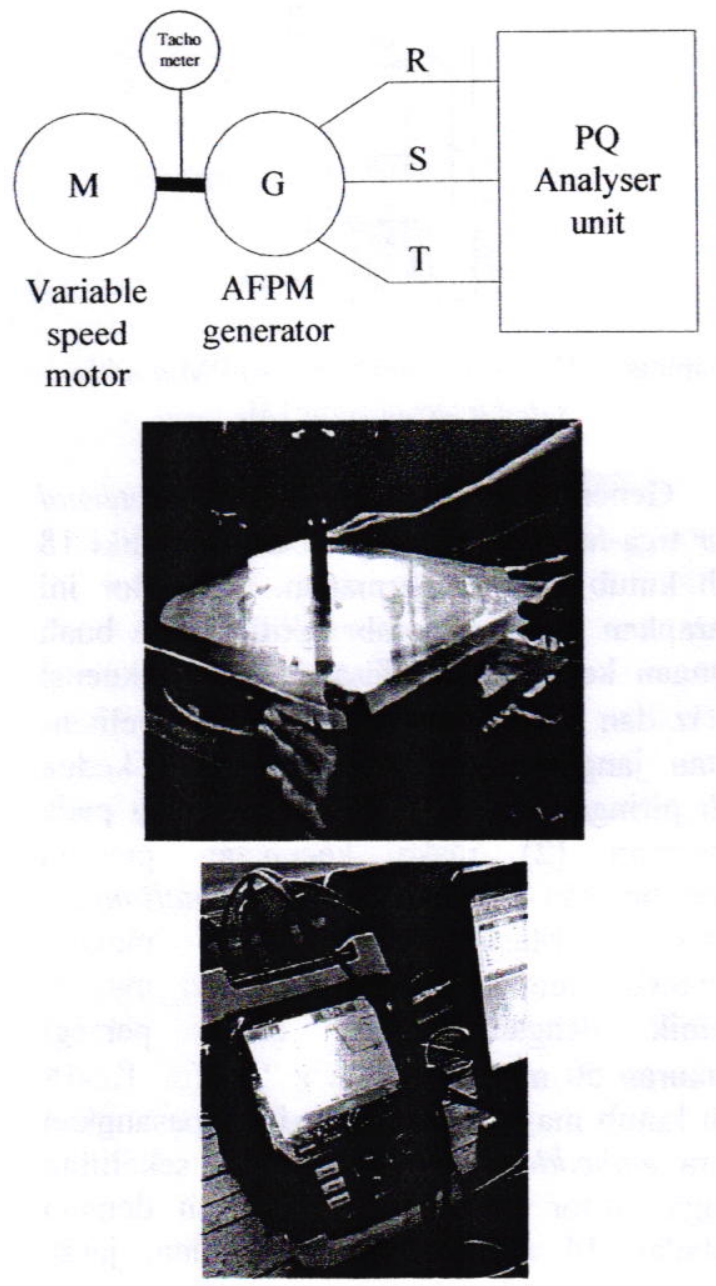

Gambar 4. Pengujian laboratorium generator AFPM double sided internal rotor tiga-fasa ganda yang telah dibuat.

Tabel 3 dan 4 menampilkan data magnituda, frekuensi dan persentase total harmonic distortion (THD)dari tegangan keluaran tiga-fasa di masing-masing piringan stator generator pada beberapa nilai putaran penggerak yang berbeda. Data dalam kedua tabel ini menunjukkan bahwa secara umum generator AFPM double sided internal rotor tiga-fasa ganda yang telah dibuat mampu menghasilkan magnituda tegangan yang hampir sama untuk setiap belitan fasanya. Pada putaran penggerak $339 \mathrm{rpm}$ yang menghasilkan frekuensi di kisaran $50 \mathrm{~Hz}$ (frekuensi jala-jala PLN), nilai rata-rata penyimpangan magnituda tegangan yang dibangkitkan generator hanya sebesar 1,5 V atau 2,5\%. Lebih lanjut, Gambar 5 menunjukkan relasi linier antara magnituda tegangan keluaran yang dibangkitkan generator terhadap putaran penggeraknya. Hasil uji ini sesuai dengan persamaan (1) yang menyatakan bahwa untuk jumlah lilitan setiap fasa belitan jangkar $\left(N_{w}\right)$ yang sama dan kuat medan 
magnetik $\left(\Phi_{m}\right)$ yang konstan maka tegangan keluaran yang dibangkitkan generator adalah berbanding lurus terhadap kecepatan putaran penggeraknya $(n)$. Pada putaran penggerak generator 339 rpm yang menghasilkan frekuensi di kisaran $50 \mathrm{~Hz}$ nilai rata-rata magnituda tegangan keluaran yang dihasilkan adalah $42,8 \mathrm{~V}$.

Dari data persentase THD pada Tabel 3 dan 4 juga terlihat bahwa generator AFPM double sided internal rotor tiga-fasa ganda yang telah dibuat mampu menghasilkan tegangan keluaran dengan bentuk mendekati sinusoidal. Nilai persentase yang berkisar antara $1,8 \%-3,4 \%$ sangat mendekati nilai persentase ideal $0 \%$ dari sebuah gelombang yang berbentuk sinusoidal murni. Pada putaran $339 \mathrm{rpm}$ yang menghasilkan frekuensi sekitar $50 \mathrm{~Hz}$, nilai rata-rata THD dari gelombang tegangan keluaran yang dihasilkan hanya sebesar $2,75 \%$ saja dengan harmonisa yang dominan adalah orde ke-3 dan ke-5.

Tabel 2. Tegangan tiga-fasa yang dibangkitkan pada piringan stator pertama.

\begin{tabular}{|c|c|c|c|c|c|c|}
\hline No & $\begin{array}{c}n \\
{[\mathrm{ipm}]}\end{array}$ & \multicolumn{3}{|c|}{$V$ [volit] } & $\begin{array}{c}f \\
{\left[\mathrm{H}_{2}\right]}\end{array}$ & $\begin{array}{c}\text { THD } \\
{[\%]}\end{array}$ \\
\hline 1 & 282 & 36 & 36 & 36,2 & 41,99 & 1,8 \\
\hline 2 & 339 & 44,9 & 39,8 & 44 & 49,87 & 3,4 \\
\hline 3 & 402 & 50,7 & 50,4 & 50,4 & 59,86 & 2,1 \\
\hline
\end{tabular}

Tabel 3. Tegangan tiga-fasa yang dibangkitkan pada piringan stator kedua.

\begin{tabular}{|c|c|c|c|c|c|c|}
\hline \multirow{2}{*}{ No } & \multirow{2}{*}{$\begin{array}{c}\text { n } \\
{[\mathrm{rpm}]}\end{array}$} & \multicolumn{3}{|c|}{ V [volt] } & \multirow{2}{*}{$f[\mathbf{H z}]$} & \multirow{2}{*}{ TH] } \\
\hline & & 18 & & & & \\
\hline 1 & 282 & 36.9 & 33.2 & 36.5 & 41.71 & 2 \\
\hline 2 & 339 & 42.8 & 42.7 & 42.6 & 50.15 & 2.1 \\
\hline 3 & 402 & 51.8 & 47.4 & 51.6 & 60.22 & 2.3 \\
\hline
\end{tabular}

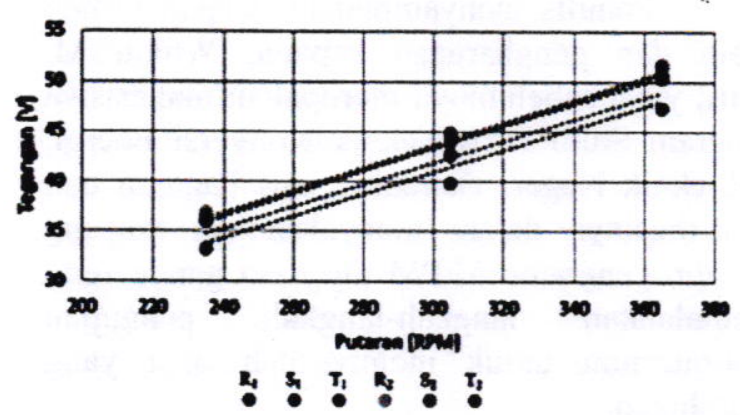

Gambar 5.Relasi antara tegangan keluaran yang dibangkitkan dan putaran penggerak generator AFPM double sided internal rotor tiga-fasa ganda.

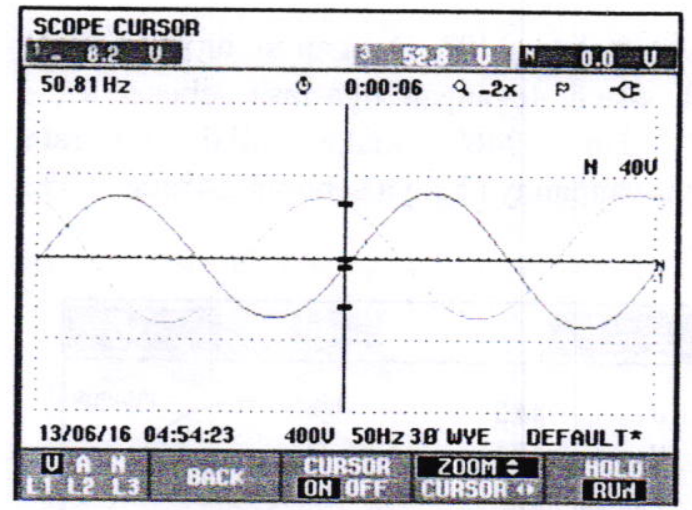

(a) Piringan stator pertama.

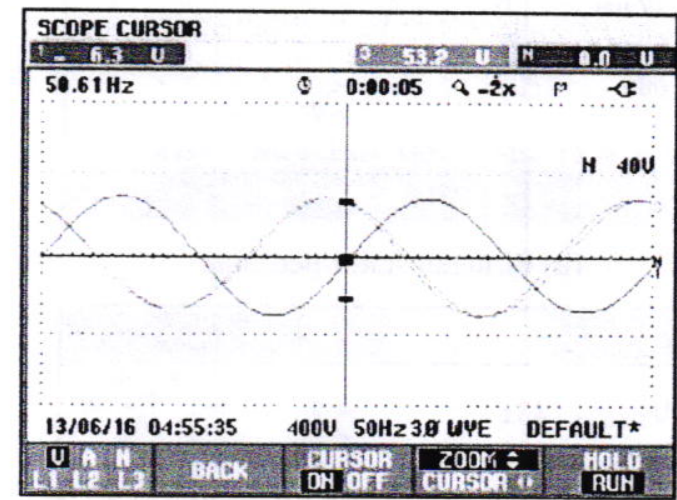

(b) Piringan stator kedua.

Gambar 6. Profil gelombang tegangan keluaran tiga-fasa yang dibangkitkan oleh generator AFPM double sided internal rotor tiga-fasa ganda pada putaran $339 \mathrm{rpm}$.

Konfirmasi lebih jauh terhadap tingginya kualitas dari bentuk gelombang tegangan keluaran tiga-fasa yang dihasilkan oleh generator AFPM double sided internal rotor tiga-fasa ganda yang telah dibuat dapat terlihat dari profil kedua buah gelombang tegangan keluaran tiga-fasa yang ditunjukkan oleh Gambar 6.

Kajian terhadap aspek keseimbangan fasa dari tegangan keluaran tiga-fasa yang dihasilkan generator dapat dilihat melalui diagram fasor seperti ditunjukkan oleh Gambar 7. Dari diagram fasor ini dapat terlihat bahwa generator AFPM double sided internal rotor tiga-fasa ganda yang telah dibuat mampu menghasilkan dua buah tegangan tiga-fasa yang memiliki keseimbangan fasa sangat baik. Pada piringan stator pertama dihasilkan tiga buah tegangan fasa $R_{1}, S_{1}$, dan $T_{1}$ dengan sudut fasa masing-masing sebesar $0^{\circ},-118^{\circ}$ dan $237^{\circ}$. Sementara pada piringan stator kedua dihasilkan tiga buah tegangan fasa $R_{2}, S_{2}$, dan $\mathrm{T}_{2}$ dengan sudut fasa masing-masing sebesar 
$0^{\circ},-121^{\circ}$ dan $-240^{\circ}$. Dengan sudut fasa ideal untuk sistem tegangan tiga-fasa sebesar $0^{\circ}$, $120^{\circ}$ dan $-240^{\circ}$ maka nilai rata-rata penyimpangannya hanya sebesar $2,4^{\circ}$ atau $1,7 \%$ saja.

\begin{tabular}{|c|c|}
\hline $44.3 \mathrm{u}$ & 4.110 ${ }^{\mathrm{N}} 0.0 \mathrm{U}$ \\
\hline$U_{1 \text { fund }} 44.3$ & \\
\hline$U_{2}$ fund 40.1 & \\
\hline$U_{3}$ fund 43.9 & \\
\hline 50.37 & \\
\hline$\delta U_{1(0)}$ & \\
\hline$\delta U_{2\left({ }^{\circ}\right)}-118$ & \\
\hline$\delta U_{3(0)} \quad-237$ & \\
\hline 13/06/16 04:54:34 & $400050 \mathrm{~Hz} 38$ WYE \\
\hline $\mid \begin{array}{ll}0 \\
4\end{array}$ & PV SLOPE \\
\hline
\end{tabular}

(a) Piringan stator pertama.

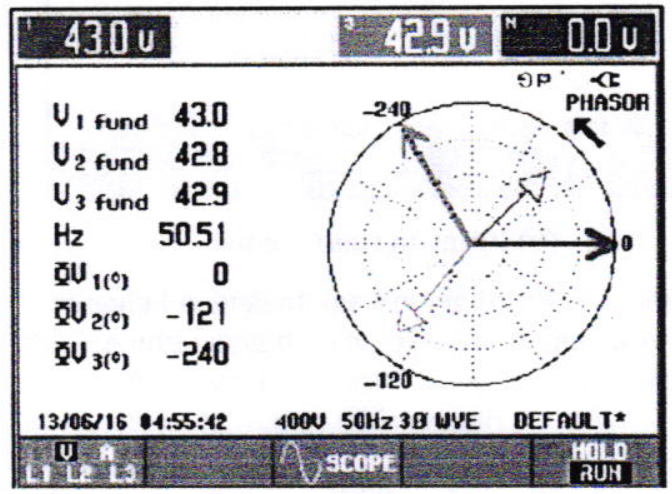

(b) Piringan stator kedua.

Gambar 7. Diagram fasor tegangan keluaran tigafasa yang dibangkitkan oleh generator AFPM double sided internal rotor tiga-fasa ganda pada putaran $339 \mathrm{rpm}$.

Untuk menunjukkan bahwa tegangan keluaran tiga-fasa yang dihasilkan generator pada piringan stator pertama memiliki pergeseran fasa $30^{\circ}$ terhadap tegangan keluaran tiga-fasa yang dihasilkan pada piringan stator kedua maka gelombang tegangan dan diagram fasor untuk tegangan fasa $R_{1}$ dan $R_{2}, S_{1}$ dan $S_{2}$ serta $T_{1}$ dan $T_{2}$ perlu diukur. Gambar 8 menampilkan hasil pengukuran gelombang tegangan dan diagram fasor untuk salah satu tegangan fasa di masingmasing piringan stator yaitu $R_{1}$ dan $R_{2}$. Dari gambar terlihat bahwa pergeseran fasa diantara keduanya adalah sebesar $32^{\circ}$ yang mendekati nilai pergeseran yang diinginkan yaitu $30^{\circ}$, atau terjadi penyimpangan sebesar $6,7 \%$ saja.
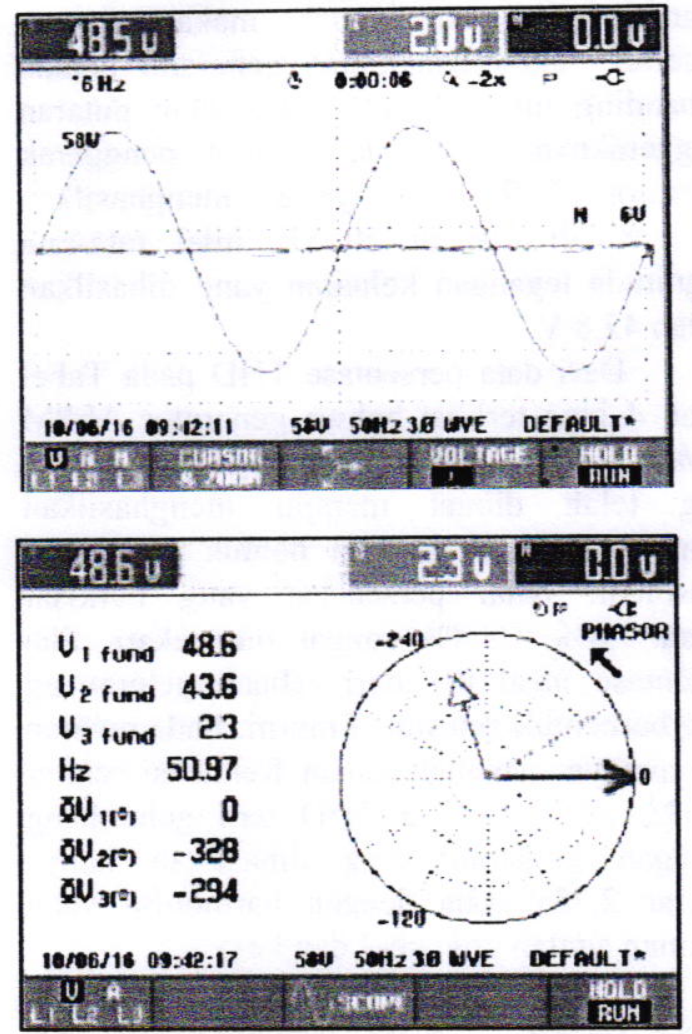

Gambar 8.Gelombang tegangan dan diagram fasor untuk salah satu tegangan fasa di masing-masing piringan stator $\left(\mathrm{R}_{1}\right.$ dan $\left.\mathrm{R}_{2}\right)$ generator AFPM double sided internal rotor tiga-fasa ganda.

\section{KESIMPULAN}

Generator AFPM tiga-fasa ganda tipe double sided internal rotor telah berhasil dibuat. Generator ini mampu menghasilkan dua buah tegangan keluaran tiga-fasa dengan pergeseran fasa $30^{\circ}$ yang memiliki bentuk gelombang mendekati sinusoidal murni serta memiliki keseimbangan magnituda dan fasa cukup baik.

\section{UCAPAN TERIMA KASIH DAN PENGHARGAAN}

Penulis menyampaikan ucapan terima kasih dan penghargaan kepada, Wulan M. Putri, yang sebelumnya merupakan mahasiswa Program Studi D-III Teknik Konversi Energi, Politeknik Negeri Bandung, atas bantuan dan kontribusinya dalam menyelesaikan rancang bangun generator AFPM tiga-fasa ganda serta menjalankan langkah-langkah pengujian laboratorium untuk memperoleh data yang diperlukan. 


\section{DAFTAR PUSTAKA}

[1] H. Piggott (2005), How to Build a Wind Turbine: The Axial Flux Windmill Plans.

[2] A. Date, A. Akbarzadeh. (2009), Design and Cost Analysis of Low Head Simple Reaction Hydro Turbine for Remote Area Power Supply, ELSEVIER. Renewable Energy. 34: 409-415.

[3] J.F. Gieras, R.J. Wang, M.J. Kamper (2004), Axial Flux Permanent Magnet Brushless Machine, Kluwer Academic Publisher, Dordrecht.

[4] A. Parviainen (2005), Design of Axial Flux Permanent Magnet Low Speed Machines and Performance Comparison Between Radial Flux and Axial Flux Machines. Finland: Lappeenranta University of Technology

[5] H. I. N. Ilham, I. M. W. Kastawan, Rusmana (2015), Pembuatan dan
Pengujian Generator Axial Flux Permanent Magnet Tipe Single Sided Slotted, Jurusan Teknik Konversi Energi, Politeknik Negeri Bandung.

[6] R. A. Nugraha, I. M. W. Kastawan, Rusmana (2016), Pembuatan dan Pengujian Pembangkitan Tegangan Generator Axial Flux Permanent Magnet Tipe Double Sided Internal Stator Slotted, Jurusan Teknik Konversi Energi, Politeknik Negeri Bandung

[7] I M. W. Kastawan, Rusmana (2016), Generator Axial Flux Permanent Magnet (AFPM) Double Sided Internal Rotor Dengan Tegangan Keluaran AC TigaFasa Sinusoidal, Prosiding Seminar Nasional Energi 2016, Program Magister Energi, Sekolah Pascasarjana, Universitas Diponegoro, Semarang, Indonesia. 